\title{
Experimental and finite element analysis of the influence of contact pressure on fretting fatigue behavior of Al-Zn-Mg alloy
}

\author{
Jiang Xiaosong*, Li Jingrui, Liu Wanxia, Zhu Degui \\ School of Materials Science and Engineering, Southwest Jiaotong University, Chengdu Sichuan 610031, P. R. China
}

Received 7 July 2014, received in revised form 14 June 2018, accepted 11 February 2019

\begin{abstract}
In this paper, experimental and finite element methods are considered for analysis of the influence of contact pressure on fretting fatigue behavior of Al-Zn-Mg alloy. Based on the fretting fatigue test apparatus with point contact, a two-dimensional implementation within the finite element software ANSYS is investigated to analyze stress distribution. A series of experimental tests are carried out so that the effect of contact pressure on the fretting fatigue characteristics and fretting fatigue life is emphatically researched. Fretting regions morphology and fretting fatigue fracture behavior have analyzed the action of fatigue and wear to determine slip amplitude effects in the fretting process in which contact pressure and tangential force are revealed as important parameters to determine crack initiation, propagation, and damage mechanisms. The calculation results indicate that for tension/compression fretting fatigue, there is a sticking region, sliding region, and opening region on the contact surface with contact pressure changing while other test parameters are invariable. When the stress amplitude is $252 \mathrm{MPa}$, with the increase of contact pressure, the cycles of cyclic softening under tension/compression fretting fatigue loading decrease, and fretting fatigue life decreases with the increase of contact pressure, which is lower than fatigue life under the same tension/compression fatigue loading. The numerical simulation reveals the merits of applying the finite element method to fretting fatigue problems, and it shows good agreement with experimental results.
\end{abstract}

Ke y w or d s: Al-Zn-Mg alloy, fretting fatigue, contact pressure, point contact, ANSYS

\section{Introduction}

Fretting fatigue is a surface damage process under the condition of cyclic loading or mechanical vibrations, and this can significantly reduce the fatigue life of components [1]. It may lead to the initiation and propagation of a crack from suffering severe distress caused by a contact problem in full or partial slip [2]. First, there are many contacting forms of fretting fatigue, which can be divided into a point, line, and surface contacts [3]. Line and surface contacts have been studied extensively [4-6]; however, there are a few reports dealing with the fretting fatigue of components under the point contact conditions by the tribology and fatigue research methods. Second, many studies have shown fretting fatigue phenomenon by various experimental or numerical test methods [7-
9]; however, a few studies focused on fretting fatigue phenomenon of $\mathrm{Al}-\mathrm{Zn}-\mathrm{Mg}$ alloy by the experimental and numerical studies. Owing to high specific mechanical properties, Al-Zn-Mg alloys are used for structural applications, which are often under the condition of cyclic loading or mechanical vibrations in the aerospace and automotive industry [10]. Third, up to 50 variables might affect the magnitude and rate of the fretting process, while the coefficient of friction, contact pressure, and magnitude of slip are considered to be the primary set of variables [11]. It is very important to study the influence of contact pressure on the fretting fatigue behavior of Al-Zn-Mg alloy. In this study, experimental and finite element analyses of contact pressure on the fretting fatigue behavior of $\mathrm{Al}-$ $\mathrm{Zn}-\mathrm{Mg}$ alloy are presented. Based on the experimental and finite element analysis of the contact pressure on

*Corresponding author: e-mail address: xsjiang@swjtu.edu.cn 

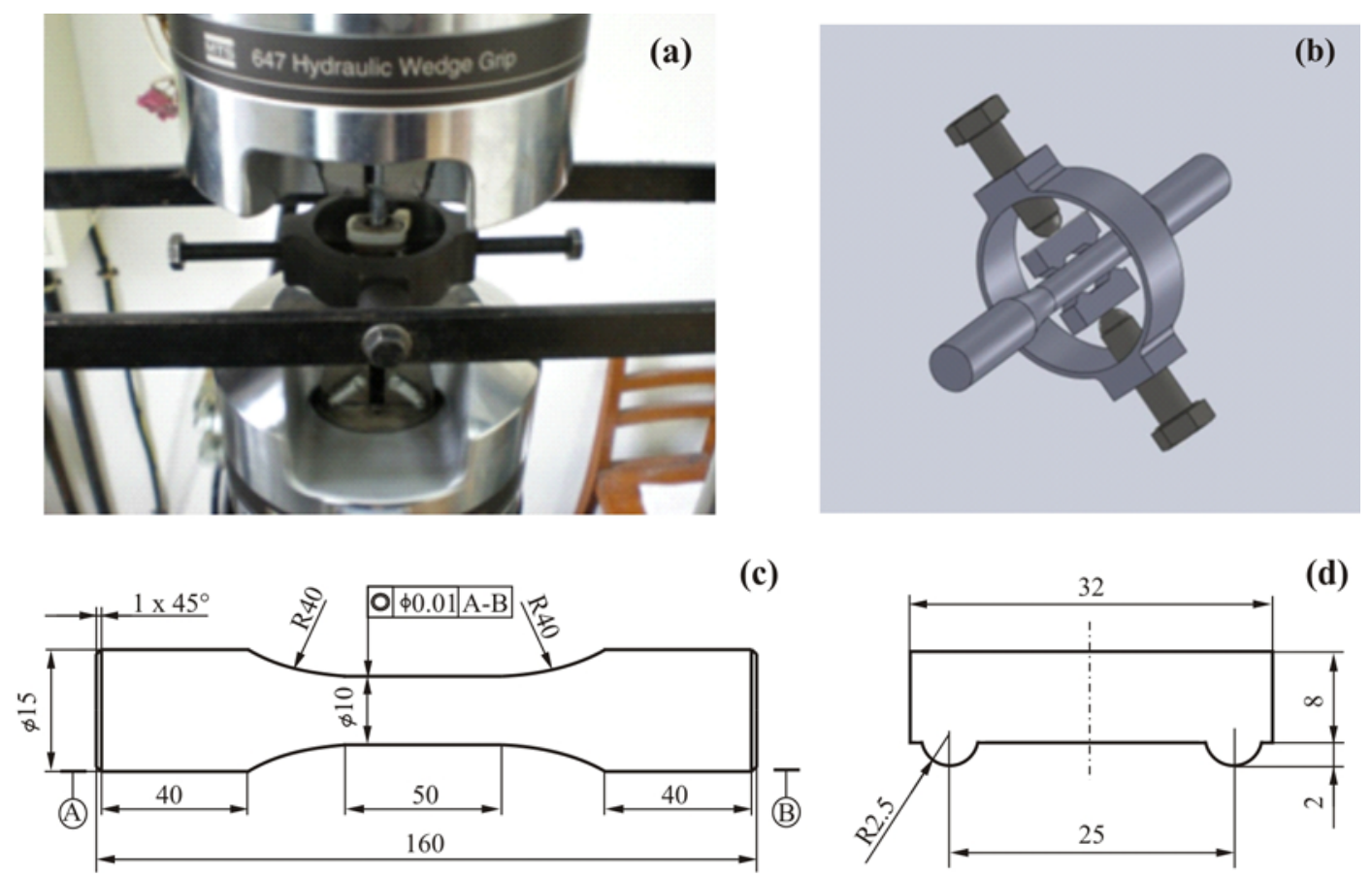

Fig. 1. System and specimen for fretting fatigue test: (a) The MTS 809 system, ND; (b) configuration for the test;

(c) smooth specimen for fretting fatigue test (unit: $\mathrm{mm}$ ); (d) pad for fretting fatigue test (unit: $\mathrm{mm}$ ).

Table 1. Mechanical properties of Al-Zn-Mg alloy

\begin{tabular}{lcccccc}
\hline Index & $\begin{array}{c}\text { Young's modulus } \\
(\mathrm{GPa})\end{array}$ & $\begin{array}{c}\text { Yield strength } \\
(\mathrm{MPa})\end{array}$ & $\begin{array}{c}\text { Tensile strength } \\
(\mathrm{MPa})\end{array}$ & $\begin{array}{c}\text { Shear modulus } \\
(\mathrm{GPa})\end{array}$ & $\begin{array}{c}\text { Reduction of area } \\
(\%)\end{array}$ & $\begin{array}{c}\text { Elongation } \\
(\%)\end{array}$ \\
\hline Numerical & 70 & 372 & 402 & 28.6 & 20 & 12 \\
\hline
\end{tabular}

the fretting fatigue behavior of $\mathrm{Al}-\mathrm{Zn}-\mathrm{Mg}$ alloy, the fretting fatigue properties and characteristic of $\mathrm{Al}$ $-\mathrm{Zn}-\mathrm{Mg}$ alloy were intensively analyzed by macroscopic and microscopic experiments.

\section{Experimental materials and methods}

The contact pads and the test specimens used in this study were prepared from $\mathrm{Al}-\mathrm{Zn}-\mathrm{Mg}$ alloy. The specimens in solution were treated at $500{ }^{\circ} \mathrm{C}$ and quenched with water at room temperature. Subsequently, they were aged at $150^{\circ} \mathrm{C}$ for $4 \mathrm{~h}$ (referred to as T6 condition). The test specimens were polished $(R a \leq 0.16)$ with silicon carbide paper and cleaned with acetone where the residual polishing marks are oriented along the length of the test specimens. The room temperature mechanical properties of $\mathrm{Al}-\mathrm{Zn}-\mathrm{Mg}$ alloy under the T6 conditions are listed in Table 1.

A schematic illustration of the contact configuration and the test device are presented in Fig. 1. The Hertzian point contact, as shown in Fig. 1, was achieved using a test specimen and a pad with a spherical contact profile. The normal force on the pads was generated by screw bolts and pad support, and the cyclic loading on the test specimen was applied using an MTS 809 system. Contact pressures were 0, 90, 180,270 , and $360 \mathrm{MPa}$ with cyclic loading stress amplitude of $252 \mathrm{MPa}$, frequency of $9 \mathrm{~Hz}$, sine waveform, and a stress ratio of -1 in a normal laboratory atmosphere. All the pads and test specimens were carefully cleaned with a solvent in an ultrasonic cleaner before and after the testing. The damage of the surface was characterized using a Quanta 200 FEG-SEM machine.

\section{Results and discussion}

\subsection{Effect of contact pressure on the contact surface partition and stress distribution}

For unidirectional tension and compression fretting fatigue test, according to the test specimen and test load symmetry, a quarter of the structure was taken to set up a finite element analysis model. For two-dimensional analysis, the nominal contact pressure $P$ is acting on the finite element nodes by a linear distribution in which $P=P_{0}(1-\xi / L)$ and 

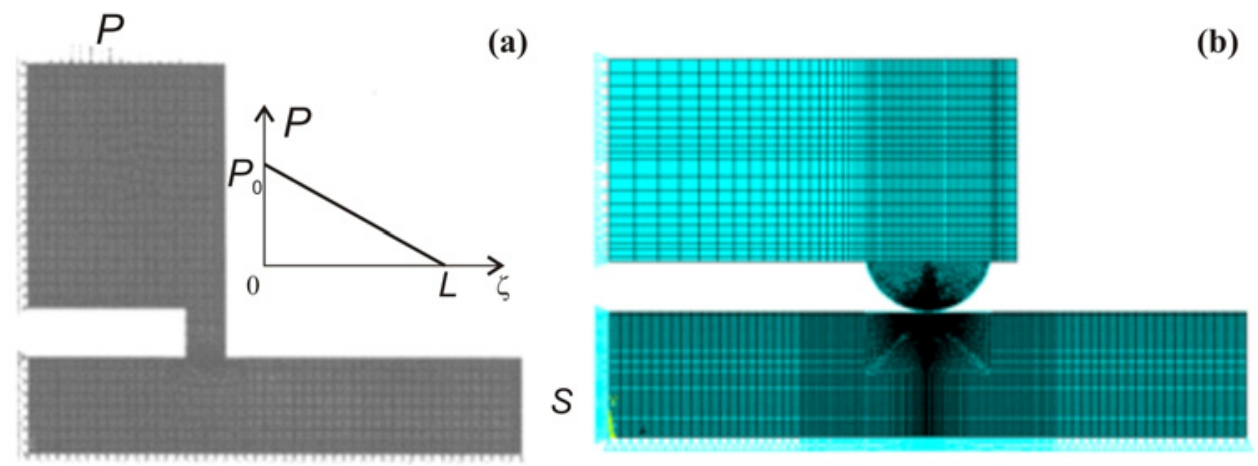

Fig. 2. (a) Micro bridge nominal stress method and (b) a finite element model for two-dimensional fretting contact analysis.
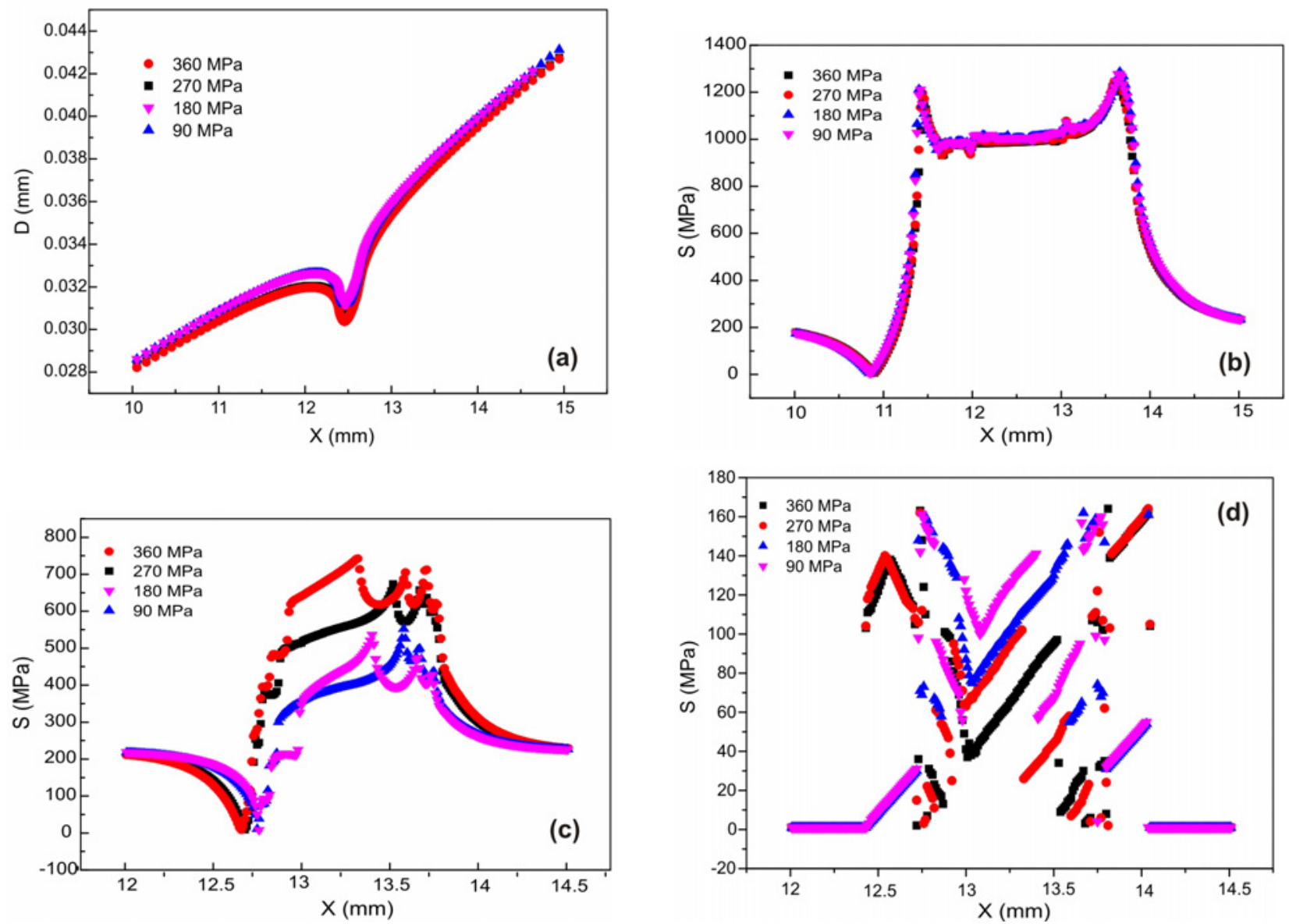

Fig. 3. Sliding distance changing with the stress amplitude variation curve and contact stress distribution curve: (a) sliding distance changing with the stress amplitude variation; (b) tensile stress distribution curve; (c) compressive stress distribution curve; (d) shear stress distribution curve.

$p_{0}=2 P / L$, where $L$ is the length of the fretting pad. Cyclic loading is evenly distributed in the endpoint element boundary nodes. The specific schematic diagram is shown in Fig. 2.

The finite element method was considered for investigating point contact fretting fatigue problem. A two-dimensional implementation was carried out by the finite element software ANSYS. Plane strain quadrilateral element PLANE42 model was used to set the model for the specimen and fretting pad, and the minimum size of the contact area grid was $4.57 \times$ $10^{-4} \mathrm{~mm}$. In total, the number of specimen units is 19 800, and nodes are 20 096; bridge units and nodes are 11167 and 11 409, respectively, and contact elements are 592 .

The effect of cyclic loading on the local point fretting contact stress distribution was studied by twodimensional finite element analysis model, where the fretting contact surface of the adhesion area and slide and open distribution of the contact stress were calcu- 

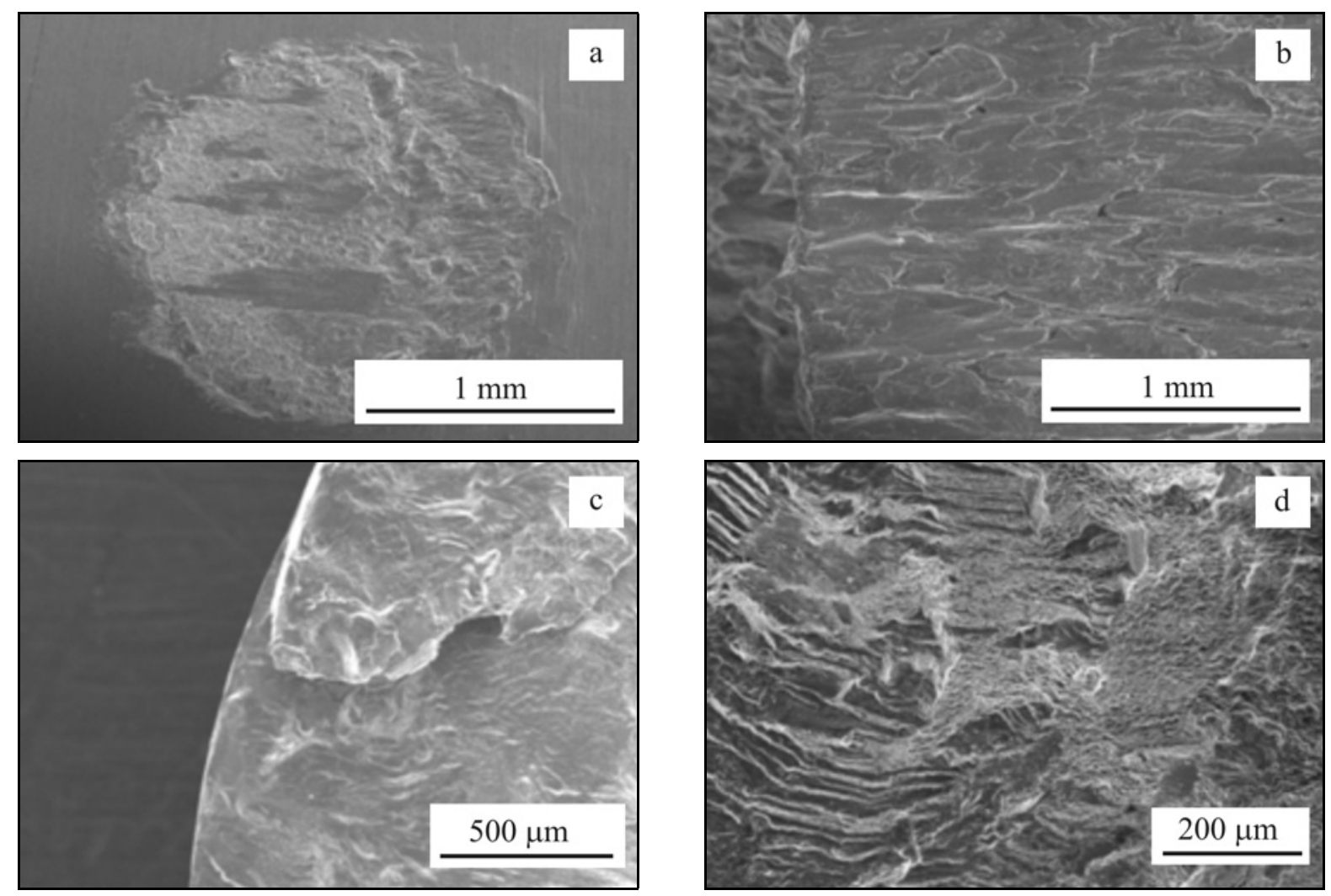

Fig. 4. SEM results of the fretting scars and fractures $(\sigma=252 \mathrm{MPa}, p=180 \mathrm{MPa})$ : (a), (b) SEM results of the fretting scars; (c) crack initiation of fracture; (d) fracture characteristic.

lated at a cycle loading of $252 \mathrm{MPa}$ and the coefficient of sliding friction of $0.4(\mu=0.4)$, while the contact pressure was $90,180,270$, and $360 \mathrm{MPa}[12]$. In this way, the effect of nominal contact pressure on the local fretting contact pressure can be discussed.

Figure 3 shows that the apparent contact surface can be divided into three regions: sticking region, sliding region, and opening region. With increasing contact pressure from 90 to $360 \mathrm{MPa}$, the sticking region increases while the sliding region decreases, and the opening region increases first and then decreases. At the junction of slipping and sticking regions, a change in tensile stress and shear stress can cause crack initiation.

Figure 3 a reveals sliding distance changing with contact pressure variation, indicating that under different contact pressure, sliding distance distribution on the entire contact edge is similar. With increasing contact pressure from 90 to $360 \mathrm{MPa}$, the sliding distance of the entire contact edge reduces gradually. Figures 3b-d show tensile stress, compressive stress, and shear stress distribution, respectively. For small contact pressure, tensile stress and shear stress have a break between the sticking and sliding regions, indicating that the scalability crack can easily initiate at the junction of the sticking and sliding regions [13]. With increasing contact pressure, the junction of the sticking and sliding regions moves to the outer space of the contact surface, suggesting that the crack initiation position moves outside with increasing contact pressure. However, when the contact pressure increases to a certain value, the tensile stress and shear stress have a break between the sliding and opening regions, indicating that the scalability crack can easily initiate at the junction of the sliding and opening regions. These results indicate that crack can easily initiate at the junction of the sliding region and sticking region or opening region.

Figure 4 shows the SEM results of $\mathrm{Al}-\mathrm{Zn}-\mathrm{Mg}$ alloy under the fretting scar and fracture at different contact pressures with an applied stress amplitude of $252 \mathrm{MPa}$. At too high contact pressure, the sticking region of the fretting fatigue contact area increases, leading to elastic deformation of the asperity, maintaining the increase in the contact state, so that the real contact area of the fretting pad and the test specimen increases, finally reducing the real contact pressure. At too low contact pressure, the fretting fatigue contact area shows overall slipping and more severe wear at the surface of the slipping area, which can lead to active particle surface spalling and wear that may be formed in the elimination of micro-cracks while reducing the crack possibility of nucleation. When the contact pressure is in a certain range, the partial slip contact surface area of the fretting pad and the test specimen is very narrow, and the contact pressure 

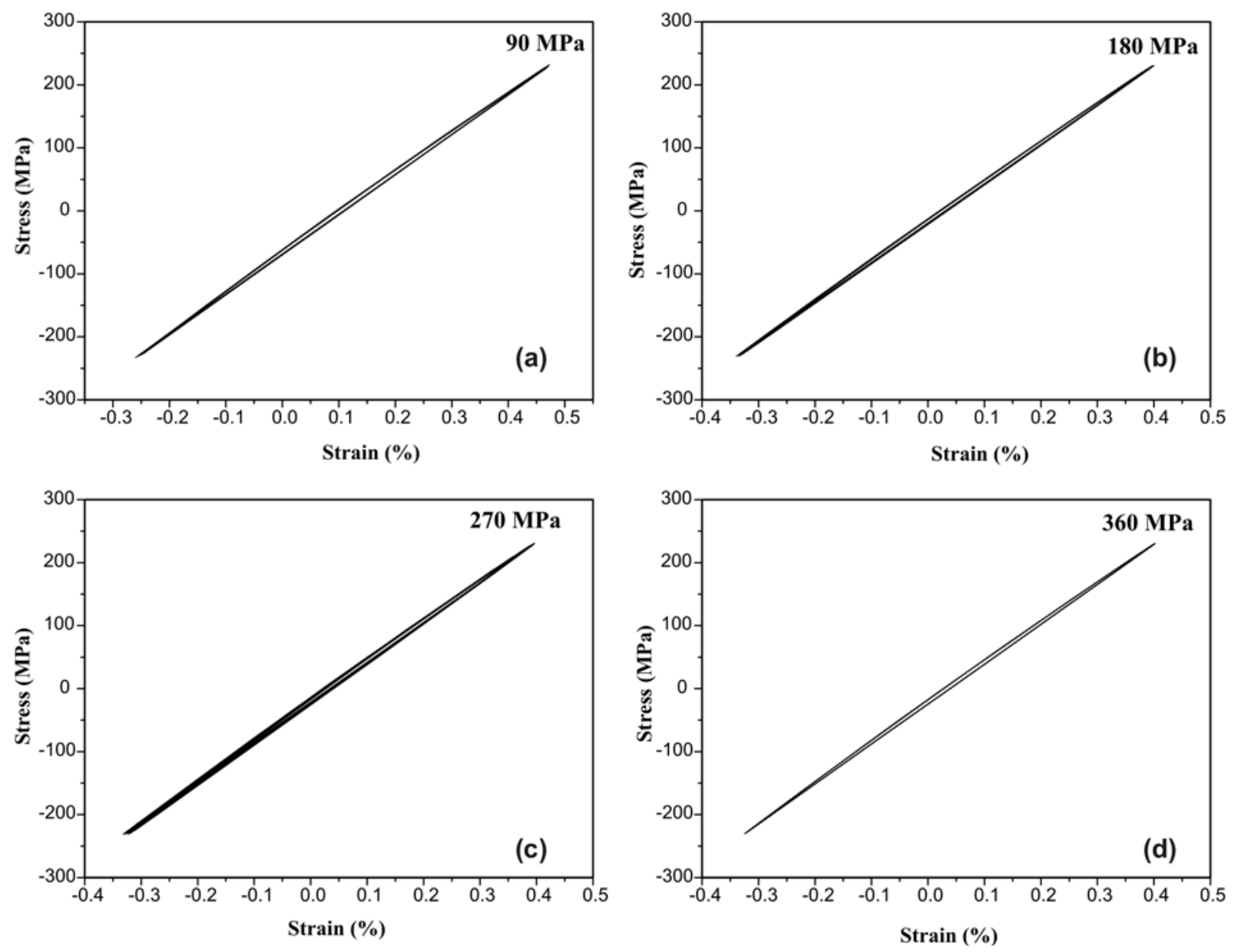

Fig. 5. Fretting fatigue hysteresis loop of Al-Zn-Mg alloy specimens under different stress amplitude: (a) $\sigma=252 \mathrm{MPa}$, $p_{1}=90 \mathrm{MPa}$; (b) $\sigma=252 \mathrm{MPa}, p_{2}=180 \mathrm{MPa}$; (c) $\sigma=252 \mathrm{MPa}, p_{3}=270 \mathrm{MPa}$; (d) $\sigma=252 \mathrm{MPa}, p_{4}=360 \mathrm{MPa}$.

at the junction between the slipping area and nonslipping area is highly concentrated to prompt crack initiation. The results under different contact pressures show that with increasing contact pressure, the elastic deformation of the fretting pad and the specimen increases, thus decreasing the slipping area of the relative slip amplitude and completely changing the contact state from partial slipping to complete slipping.

The finite element simulation results show that at constant stress amplitude of the fretting pad and the specimen, the compressive stress and shear stress change with changing contact pressure, and the maximum shear stress increases with increasing contact pressure, easily procuring the surface microcrack. Such high contact pressure can easily form fretting fatigue crack source or cause subsurface defects through the surface and become the source of cracks at the fretting contact region [14]. The finite element simulation results show that fretting fatigue crack initiates in the fretting-mixing region and can be explained by the friction cyclic stress mechanism to illustrate the characteristics of the fretting scar and fracture.

\subsection{Effect of contact pressure on the behavior of fretting fatigue}

The effect of contact pressure on the elastic-plastic deformation characteristics of $\mathrm{Al}-\mathrm{Zn}-\mathrm{Mg}$ alloy was investigated by the fretting fatigue cyclic stress-strain curves of $\mathrm{Al}-\mathrm{Zn}-\mathrm{Mg}$ alloy under different contact pressures, as shown in Fig. 5. The figure shows that when the stress amplitude is $252 \mathrm{MPa}$, the stressstrain curve is surrounded by a smaller area. It illuminates $\mathrm{Al}-\mathrm{Zn}-\mathrm{Mg}$ alloy, which has been under an apparent plastic deformation [15]. With increasing contact pressure, the stress-strain curve does not show any significant change, indicating that $\mathrm{Al}-\mathrm{Zn}-\mathrm{Mg}$ alloy is more evidently under plastic deformation.

To study the effect of contact pressure on the fretting fatigue properties of $\mathrm{Al}-\mathrm{Zn}-\mathrm{Mg}$ alloy, the cyclic characteristics of Al-Zn-Mg alloy are shown in Fig. 6, indicating that with increasing contact pressure from 90, 180, 270 to $360 \mathrm{MPa}$, the displacement amplitude is stable at $0.4 \mathrm{~mm}$ after loop stability. Within the first 10 cycles, displacement amplitude increases rapidly with increasing number of cycles and then becomes 

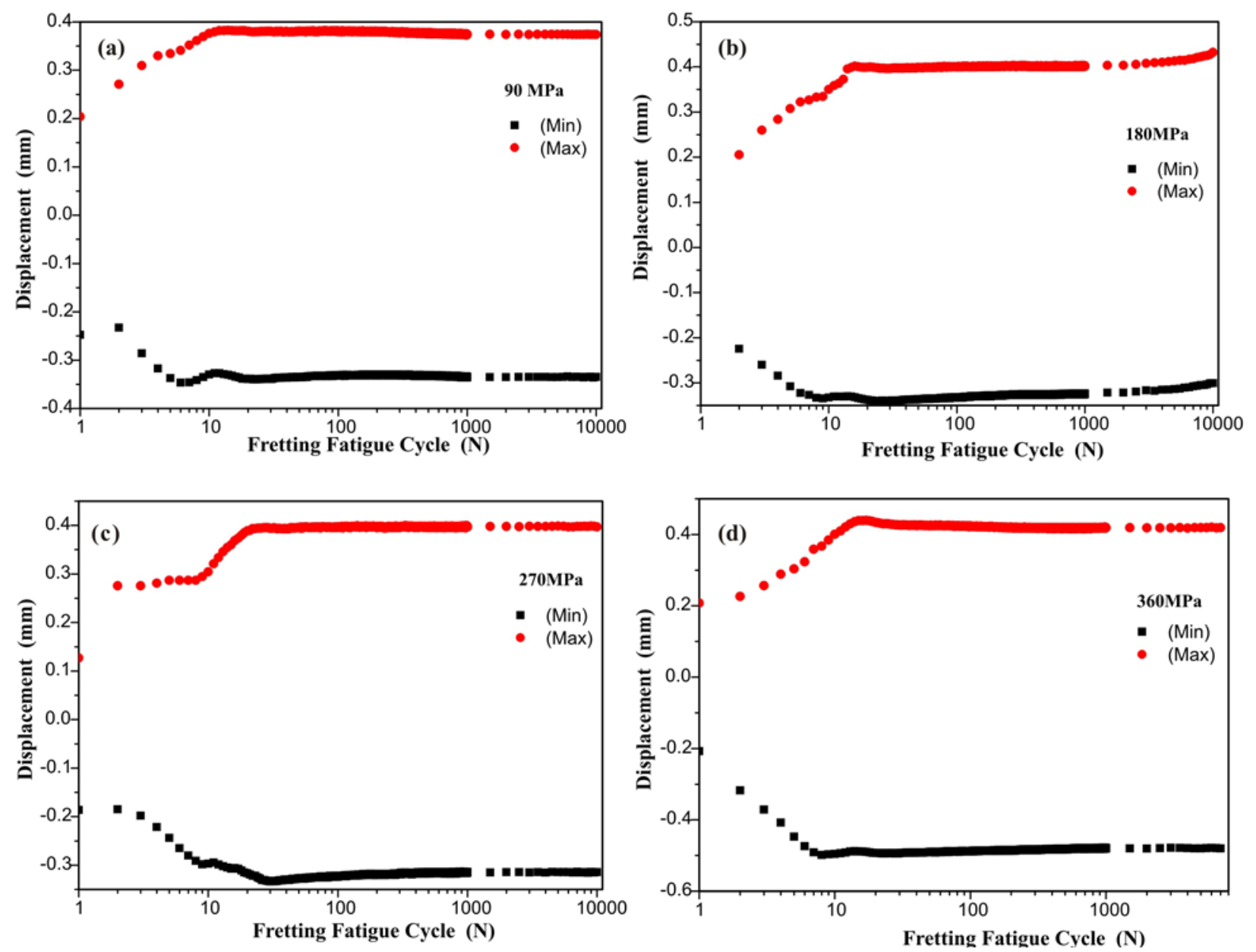

Fig. 6. Displacement amplitude-cycle curve of Al-Zn-Mg alloy specimens under different stress amplitude: (a) $\sigma=252 \mathrm{MPa}$, $p_{1}=90 \mathrm{MPa}$; (b) $\sigma=252 \mathrm{MPa}, p_{2}=180 \mathrm{MPa}$; (c) $\sigma=252 \mathrm{MPa}, p_{3}=270 \mathrm{MPa}$; (d) $\sigma=252 \mathrm{MPa}, p_{4}=360 \mathrm{MPa}$.

constant and stabilizes after $\sim 10$ cycles. Then, from 10 cycles to 30 cycles, with an increasing number of cycles, the displacement amplitude still increases; however, the rate of increase is less than before as the displacement amplitude increase is mainly due to cyclic softening. After 30 cycles, the amplitude can be stable and maintains at a constant value. However, the results show that with increasing contact pressure, the number of cycles required to maintain a constant value of the displacement amplitude decreases because the fretting friction increases with increasing contact pressure. Meanwhile, friction changes dramatically during cycles, with increasing contact pressure fretting friction faster entering into the stable region. Because the relationship between the displacement amplitude and cycles is related to the cyclic softening of $\mathrm{Al}-\mathrm{Zn}-\mathrm{Mg}$ alloy, the fretting friction affects the displacement amplitude.

At stress amplitude of $252 \mathrm{MPa}$, with increasing contact pressure, the fretting fatigue life of $\mathrm{Al}-\mathrm{Zn}-\mathrm{Mg}$ alloy is shown in Fig. 7, indicating that the fretting fatigue life of $\mathrm{Al}-\mathrm{Zn}-\mathrm{Mg}$ alloy is sensitive to the contact pressure. With increasing contact pressure, the

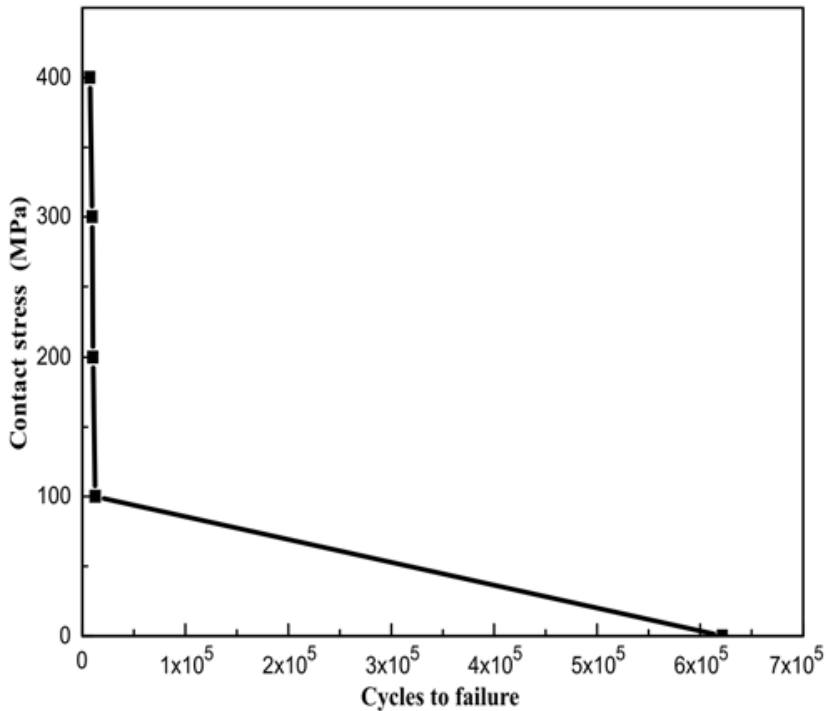

Fig. 7. Fretting fatigue life of Al-Zn-Mg alloy under different stress pressure. 
fretting fatigue life of $\mathrm{Al}-\mathrm{Zn}-\mathrm{Mg}$ alloy shows a general decline trend under different contact pressure ranges, and the fretting fatigue life decreases with increased contact pressure with different amplitudes. In the process of fretting fatigue, specimens are subjected to cyclic loading and contact pressure results in the joint action of fretting wear and fretting fatigue, increasing damage to the specimen. Simultaneously, the fretting wear continues to accumulate with an increasing number of cycles. With increasing stress amplitude, microcrack initiation and propagation increases, which reduces the fretting fatigue life. At the same time, the specimens were also compared under different contact pressures and without contact pressure, and the results show that the specimens' life is far below their fatigue life. When the contact pressure changes from 90 to $180 \mathrm{MPa}$, the fretting fatigue life reduction magnitude is far less than that of the contact pressure change from 270 to $360 \mathrm{MPa}$.

In the fretting fatigue process, specimens are subjected to cyclic loading and the contact pressure. The joint action of the fretting wear and fretting fatigue increases the damage of the specimens, changing the contact zone status with increasing contact pressure. At the higher stress amplitude level, the specimens are in the joint action of the fretting wear and fretting fatigue for only a short time, and thus the cumulative damage effect is not apparent. At a contact pressure of $90 \mathrm{MPa}$, the fretting zone is in a partially slipping zone or slipping zone, and fretting wear dominates when the fretting wear and fatigue are in the joint action [16]. When the contact pressure is $270 \mathrm{MPa}$, the fretting fatigue life of $\mathrm{Al}-\mathrm{Zn}-\mathrm{Mg}$ alloy is relatively short, and the fretting zone in the adhesion area fretting dominates under the joint action of fretting wear and fatigue. Simultaneous effects of the fretting wear due to the gap effect can change the fretting fatigue life magnitude to a greater extent.

\section{Conclusions}

1. The finite element calculation results indicate that for tension/compression fretting fatigue, there are a sticking region, sliding region, and opening region on the contact surface with changing contact pressure keeping other test parameters invariable. The joint action of the fretting wear and fretting fatigue causes accumulation of damage on the specimens, changing the contact zone status with increasing contact pressure.
2. At a stress amplitude of $252 \mathrm{MPa}$, with increasing contact pressure, the cycles of cyclic softening under tension/compression fretting fatigue loading decrease, and the fretting fatigue life decreases with increasing contact pressure and is lower than the fatigue life under the same tension/compression fatigue loading.

\section{References}

[1] Flicek, R., Hills, D. A., Dini, D.: Fatigue \& Fracture of Engineering Materials \& Structures, 34, 2011, p. 974. doi:10.1111/j.1460-2695.2012.01694.x

[2] Hills, D. A.: Wear, 175, 1994, p. 107. doi:10.1007/978-94-015-8281-0

[3] Witkowsky, B. U., Birch, P. R., Dominguez, J., Suresh, S.: Materials \& Structures, 22, 1999, p. 307. doi:10.1046/j.1460-2695.1999.00145.x

[4] Zhang Dekun, Ge Shirong: Mocaxue Xuebao/Tribology, 24, 2004, p. 355. (In Chinese) doi:10.3321/i.issn:1004-0595.2004.04.015

[5] Liu, B., He, G., Jiang, X., Zhu, M.: Materials \& Structures, 34, 2011, p. 974. doi:10.1111/i.1460-2695.2011.01586.x

[6] Nesládek, M. Spaniel, M., Jurenka, J., Růžička, J., Kuželka, J.: International Journal of Fatigue, 44, 2012, p. 61. doi:10.1016/j.ijfatigue.2012.05.015

[7] Zhu, Y., Kang, G., Ding, J., Zhu, M. H.: Fatigue \& Fracture of Engineering Materials \& Structures, 36, 2013, p. 127. doi:10.1111/j.1460-2695.2012.01705.x

[8] Fadel, A. A., Rosa, D., Murça, L. B., Fereira, J. L. A., Araújo, J. A.: International Journal of Fatigue, 42, 2012, p. 24. doi:10.1016/j.ijfatigue.2011.03.007

[9] Noraphaiphipaksa, N., Kanchanomai, C., Mutoh, Y.: Engineering Fracture Mechanics, 112-113, 2013, p. 58. doi:10.1016/j.engfracmech.2013.10.007

[10] Werenskiold, J. C., Deschamps, A., Bréchet, Y.: Materials Science and Engineering A, 293, 2000, p. 267. doi:10.1016/S0921-5093(00)01247-8

[11] Madge, J. J., Leen, S. B., McColl, I. R., Shipway, P. H.: Wear, 262, 2007, p. 1159. doi:10.1016/j.wear.2006.11.004

[12] Jian Hai-gen, Jiang Feng, Wen Kang, Long Jiang, Hong-Feng Huang, Li-Li Wei: Transactions of Nonferrous Metals Society of China, 19, 2009, p. 1031. doi:10.1016/S1003-6326(08)60402-1

[13] Madge, J. J., Leen, S. B., Shipway, P. H.: International Journal of Fatigue, 30, 2008, p. 1509. doi:10.1016/j.ijfatigue.2008.01.002

[14] McCarthy, O. J., McGarry, J. P., Leen, S. B.: Wear, 305, 2013, p. 100. doi:10.1016/j.wear.2013.05.012

[15] Renard, A., Cheng, A. S., De La Veaux, R., Laird, C.: Materials Science and Engineering, 60, 1983, p. 113. doi:10.1016/0025-5416(83)90180-5

[16] Ferré, R., Fouvry, S., Berthel, B., Ruiz-Sabariego, J.A.: International Journal of Fatigue, 54, 2012, p. 56. doi:10.1016/j.ijfatigue.2013.03.005 